\title{
Assessing the Proliferation Resistance of Innovative Nuclear Fuel Cycles*
}

\author{
R. Baria , J. Roglans ${ }^{b}$, R. Denning ${ }^{c}$, and S. Mladineo ${ }^{d}$ \\ a. Brookhaven National Laboratory, Upton, NY, 11973-5000 USA \\ b. Argonne National Laboratory, Argonne, $\amalg, 60439$ USA \\ c. Battelle Memorial Institute, Columbus, OH, 43201-2693 USA \\ d. Pacific Northwest National Laboratories, Richland, WA, 99352 USA
}

\begin{abstract}
The National Nuclear Security Administration is developing methods for nonproliferation assessments to support the development and implementation of U.S. nonproliferation policy. This paper summarizes the key results of that effort. Proliferation resistance is the degree of difficulty that a nuclear material, facility, process, or activity poses to the acquisition of one or more nuclear weapons. A top-level measure of proliferation resistance for a fuel cycle system is developed here from a hierarchy of metrics. At the lowest level, intrinsic and extrinsic barriers to proliferation are defined. These barriers are recommended as a means to characterize the proliferation characteristics of a fuel cycle. Because of the complexity of nonproliferation assessments, the problem is decomposed into: metrics to be computed, barriers to proliferation, and a finite set of threats. The spectrum of potential threats of nuclear proliferation is complex and ranges from small terrorist cells to industrialized countries with advanced nuclear fuel cycles. Two general categories of methods have historically been used for nonproliferation assessments: attribute analysis and scenario analysis. In the former, attributes of the systems being evaluated (often fuel cycle systems) are identified that affect their proliferation potential. For a particular system under consideration, the attributes are weighted subjectively. In scenario analysis, hypothesized scenarios of pathways to proliferation are examined. The analyst models the process undertaken by the proliferant to overcome barriers to proliferation and estimates the likelihood of success in achieving a proliferation objective. An attribute analysis approach should be used at the conceptual design level in the selection of fuel cycles that will receive significant investment for development. In the development of a detailed facility design, a scenario approach should be undertaken to reduce the potential for design vulnerabilities. While, there are distinctive elements in each approach, an analysis could be performed that utilizes aspects of each approach.
\end{abstract}

\section{Introduction}

The National Nuclear Security Administration (NNSA) is developing methods for nonproliferation analyses to support the development and implementation of U.S. nonproliferation policy. A Nonproliferation Assessment Methodology (NPAM) Working Group, comprised of representatives from the DOE laboratories and academia, was established to prepare guidelines [1] for the selection of methods and for the performance of nonproliferation assessments.

NNSA directed the Working Group to place initial emphasis on fuel cycle related issues because of a recognized need to support DOE initiatives related to new reactor designs. However, the methods have broad applicability to a spectrum of proliferation issues.

\footnotetext{
* This work is performed under the auspices of the U.S. Department of Energy under Contract No. DE-AC02-98CH10886.
} 


\section{Objectives of Nonproliferation Assessment}

NNSA provides technical input to policy makers that establish U.S. nonproliferation policies. Within the context of policy development, the purpose of a nonproliferation assessment is to examine the relative merits of alternative actions or propositions relative to controlling the potential for proliferation. For example, as illustrated in Figure 1, the purpose of the analysis may be to compare the proliferation resistance of Fuel Cycle Option A with Fuel Cycle Option B. In order to satisfy the objectives of the analysis, the analyst needs measures of proliferation resistance to indicate whether $A$ is better or worse than $B$. The analyst also needs to know the uncertainty in the measures to be able to determine whether the indicated difference between $A$ and $B$ is significant. Thus, as indicated in Figure 2, the comparison between Fuel Cycle Option A and Fuel Cycle Option B may have to be interpreted within the context of the uncertainty. Whereas the policy maker may conclude from examining Figure 1 that Fuel Cycle A is more proliferation resistant than Fuel Cycle B, the more appropriate conclusion may be the one drawn from Figure 2 that Fuel Cycle $A$ is probably more proliferation resistant than Fuel Cycle B.

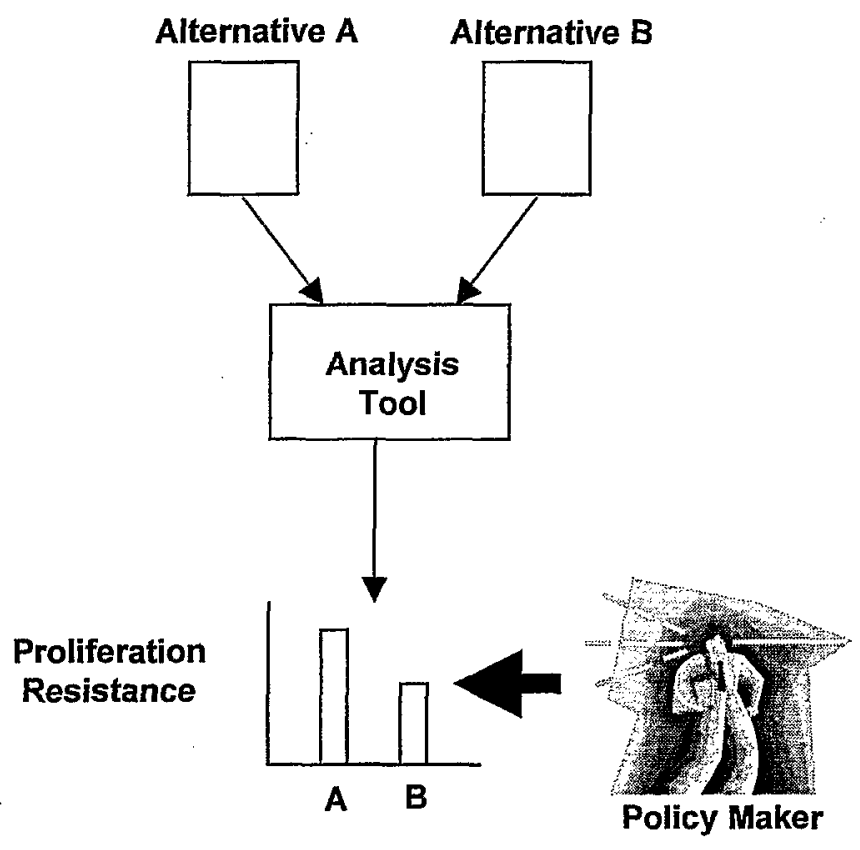

Figure 1. Concept of a Nonproliferation Assessment Study 


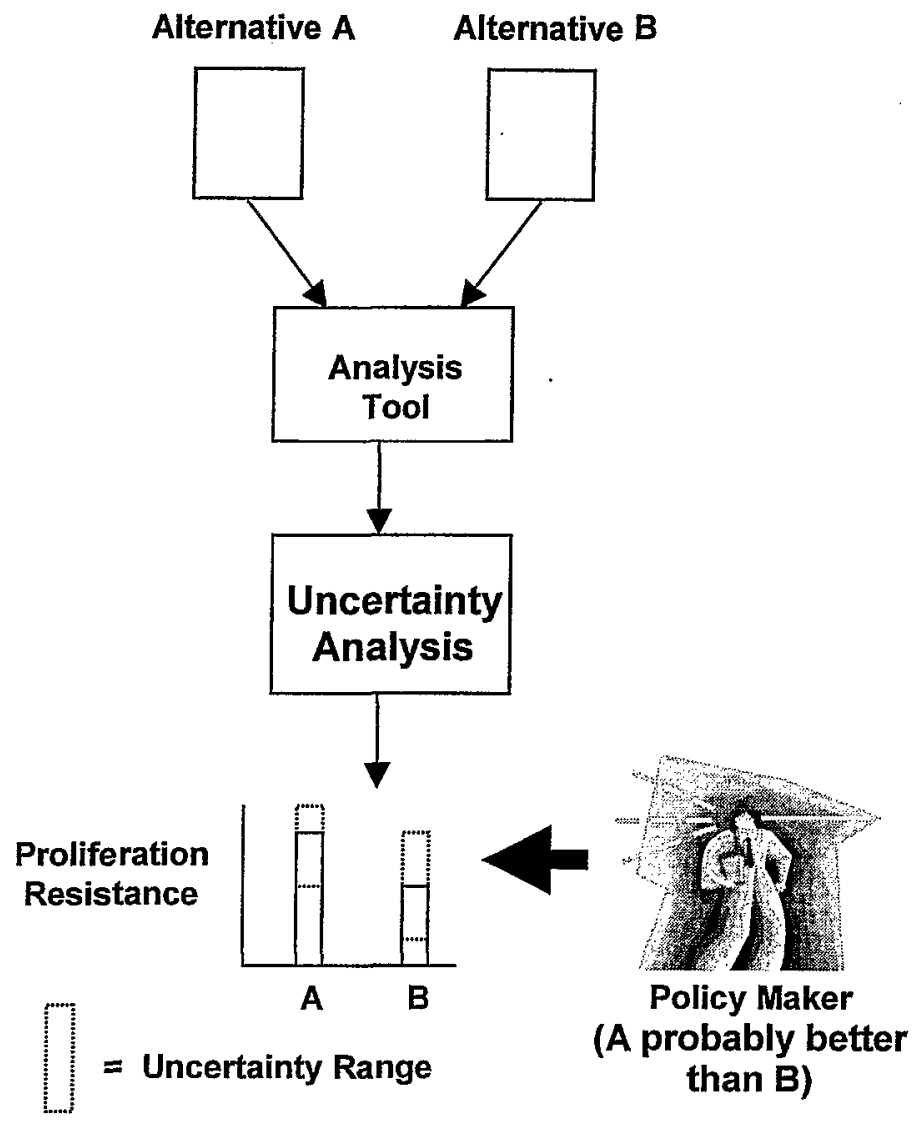

Figure 2. Results with Uncertainties

\section{Content of Guidelines Document}

Figure 3 illustrates the steps to be taken in performing a nonproliferation assessment in support of policy development. Each step is addressed in the guidelines document. Within the first step of framing the problem, the analyst in collaboration with the policy-maker must clearly state the objectives of the analysis. The analyst must then develop an approach to attack the problem. Based on their experience, nonproliferation analysts have developed some preferred approaches to decomposing nonproliferation problems involving selection of analysis methods, threat description, identification of barriers to proliferation, the definition of metrics, and system segmentation.

\section{Methods of Analysis}

One of the objectives of the guidelines document is to provide a toolbox of tools and methods that are available to the analyst to support the performance of a nonproliferation assessment. The applicability of a variety of analytical methods is discussed in the guidelines document, including some generic tools that could be applied in any study such as uncertainty analysis, sensitivity analysis, logic diagrams, and approaches to expert elicitation.

Two general categories of methods have been used historically as the basis for nonproliferation assessments: attribute analysis and scenario analysis. 
Attribute analysis. In this approach, attributes of the systems being evaluated (often fuel cycle systems) that affect their proliferation potential are identified. For a particular system under consideration, the attributes are weighted subjectively. Typically, these studies are more qualitative than the scenario analysis studies. There is an extensive history of the use of formal methods of decision theory (such as multi-attribute utility theory) to assist in policy development using this type of approach. 


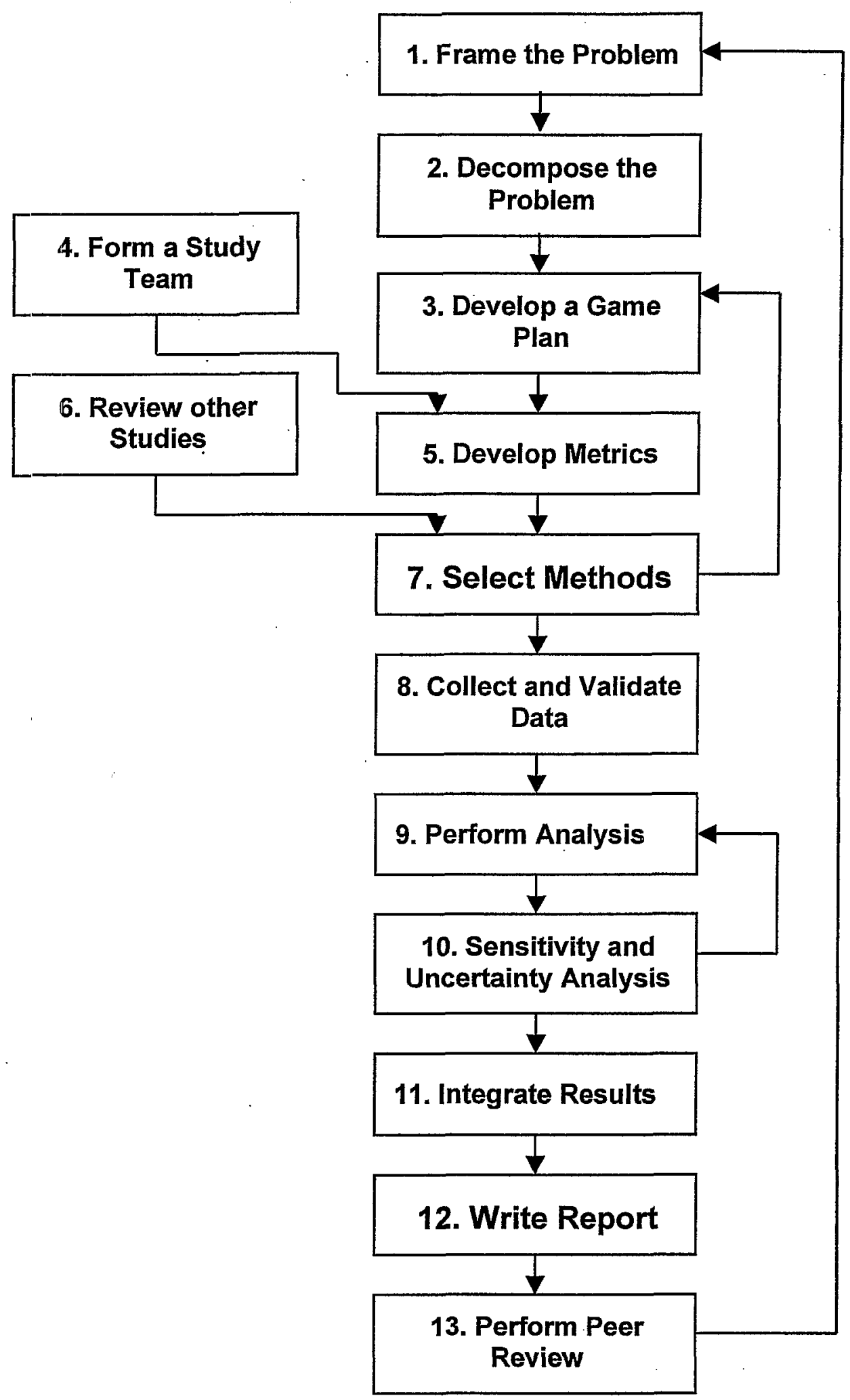

Figure 3. Elements of an Assessment Project 
Scenario analysis. In these studies, hypothesized scenarios of pathways to proliferation are examined. The analyst models the process undertaken by the proliferant to overcome barriers to proliferation and estimates the likelihood of success in achieving a proliferation objective. Typically, these studies use logic modeling techniques (often probabilistic techniques). The results are quantitative but rely, in some respects, on subjective judgments of experts.

The Working Group identified two-sided methods as also having significant potential to support nonproliferation assessment.

Two-sided methods. These methods examine the interplay between opponents. Wargaming is a two-sided approach that has been used extensively in other applications. A wargame [2] is a role-playing exercise where human participants, often with opposing goals, make sequential decisions to allow a scenario to unfold. Wargames appear to have promising potential to provide policy insights for nonproliferation issues that are not addressed effectively by other methods.

These different categories of methods have complementary roles in the development of nonproliferation policy. Either attribute analysis or scenario analysis can provide the basis for an integrated nonproliferation assessment that assesses measures of the proliferation potential of alternative systems. These two types of approaches have strengths and weaknesses that determine the type of study for which each is preferred. Wargames are not competitive with attribute analysis or scenario analysis for the performance of integrated assessments. The results of a wargame represent a possible outcome but not necessarily the most likely outcome of an interaction. They can, however, provide valuable insights into the thought processes of adversaries as input to an integrated assessment.

The types of policy issues for which NNSA provides technical support can be addressed by the following combinations of nonproliferation assessment characteristics:

- System - materials, facilities, processes, safeguards

- Commercial fuel cycle

- Nuclear weapons infrastructure

- Design level

- Detailed

- Conceptual

- Location

- Domestic

- International - generic

- International - regional specific

In addition, geopolitical analyses may be required to support "regional security" related policies.

In evaluating the strengths and weaknesses of the different analysis approaches, the Working Group concluded that the principal discriminating features of the assessment are the detail of design information and the amount of time (and associated effort) available to perform the study. Table 1 summarizes the strengths and weaknesses of the analysis approaches for these different analysis constraints. 
Table 1. Strengths and Weaknesses of Assessment Approaches as a Function of Analysis Constraints

\begin{tabular}{|c|c|c|c|c|c|}
\hline System & 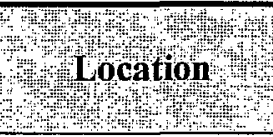 & $\begin{array}{l}\text { Design } \\
\text { Detail } \\
\text { Duration }\end{array}$ & $\begin{array}{l}\text { Attribute } \\
\text { Analysis }\end{array}$ & $\begin{array}{l}\text { Scenario } \\
\text { Analysis }\end{array}$ & $\begin{array}{l}\text { Wart } \\
\text { gaming }\end{array}$ \\
\hline \multirow{8}{*}{$\begin{array}{l}\text { Nuclear Fuel Cycle } \\
\text { or Nuclear Weapons } \\
\text { Infrastructure }\end{array}$} & \multirow{8}{*}{$\begin{array}{c}\text { Domestic, } \\
\text { Foreign-Generic, } \\
\text { or Region } \\
\text { Specific }\end{array}$} & Detailed & \multirow{2}{*}{$\mathrm{M}$} & \multirow{2}{*}{$\mathrm{M}$} & \multirow{2}{*}{$\mathrm{L}$} \\
\hline & & Short & & & \\
\hline & & Detailed & \multirow{2}{*}{$\mathrm{H}$} & \multirow{2}{*}{$\mathrm{H}$} & \multirow{2}{*}{ M } \\
\hline & & Long & & & \\
\hline & & Conceptual & \multirow{2}{*}{$\mathrm{H}$} & \multirow{2}{*}{ L } & \multirow{2}{*}{$\mathbf{M}$} \\
\hline & & Short & & & \\
\hline & & Conceptual & \multirow{2}{*}{$\mathrm{H}$} & \multirow{2}{*}{$\mathrm{H}$} & \multirow{2}{*}{$\mathrm{H}$} \\
\hline & & Long & & & \\
\hline \multirow[t]{3}{*}{ Geopolitical } & \multirow{3}{*}{$\begin{array}{l}\text { Global or } \\
\text { Regional }\end{array}$} & & \multirow{2}{*}{$\mathrm{M}$} & \multirow{2}{*}{ L } & \multirow{2}{*}{$\mathrm{H}$} \\
\hline & & Short & & & \\
\hline & & Long & $\mathbf{M}$ & L & $\mathrm{H}$ \\
\hline
\end{tabular}

*Wargaming typically is only one element of a nonproliferation analysis.

High (H), Medium (M) and Low (L) represent the strength of the analysis approach for the indicated level of design detail and project duration. The dividing point between a short duration and a long duration project is assumed to be one month. Sometimes requests for policy input can be as short as one day. Unless there is substantial information already available on the topic, it is difficult to use any of these methods in a period of less than one week. An in-depth, integrated assessment is expected to require approximately six months.

Scenario analysis methods can be applied at a conceptual level but their strength is in studies in which detailed design information is available to support the analysis. This type of assessment requires substantial time and effort. Scenario analysis methods can be important design tools that are used in the identification and correction of design vulnerabilities.

Attribute analysis methods do not require the level of detailed design information as scenario analysis methods. They can, however, require substantial effort. The Analytic Hierarchy Process [3], an attribute method, can be used for quick response projects. However, the reliability of the result depends highly on the expertise of the experts that provide input to the process.

Some time and effort is required to set up a wargaming exercise. However, the actual execution of the exercise is short. Thus, it is quite practical to obtain meaningful results in less than one month. Wargames tend to provide insights that are of value in developing a better understanding of the conflict between the proliferant and the act. Wargames are usually only one element of a larger nonproliferation assessment.

\section{Barriers to Proliferation}

One of the strategies that is typically taken in nonproliferation analysis is to identify barriers to proliferation and to determine how effective these barriers are to deterring proliferation. This strategy is used both by scenario-based and attribute-based approaches. However, the manner in which they assess the effectiveness of barriers differs.

Barriers are typically characterized as either intrinsic, features that are inherent to a particular fuel cycle system, or extrinsic, administratively-added security features such as physical 
protection and international safeguards. A listing of barriers is provided in Table 2. Also included in the table are the attributes of that barrier that affect proliferation potential. The nature of the proliferation threat can impact the relative effectiveness of intrinsic and extrinsic barriers. If a nation state decides to remove its facilities from IAEA safeguards and to use its commercial nuclear facilities to produce weapons material, extrinsic barriers would become completely ineffective in deterring the production of weapons material but intrinsic barriers could still be in place.

\section{Threat Description}

Another standard strategy for the decomposition of nonproliferation problems is to define a set of threats and to evaluate the proliferation resistance of the option under consideration for each threat separately. Consider, for example, a fuel cycle facility that is under IAEA safeguards. One threat could be a country with a high level of technical competence that decides to divert material covertly. Another threat is a small subnational group that attacks the facility and attempts to escape with weapons material. The relative resistance to these different proliferation threats varies depending on the alternative fuel cycle system under consideration. Table 3 provides a possible characterization of threat categories.

\section{Metries}

After the objectives of the study have been clearly defined, the analyst must determine the metrics or measures (high level metrics) that will be used to characterize the proliferation resistance of the alternatives being evaluated. The guidelines review metrics that have been used in previous studies. A general hierarchy of metrics, as illustrated in Figure 4, is developed to show how lower level metrics can be related to the high level measures that will be used by the decision maker to decide which are the preferred alternatives. For nonproliferation studies that compare the proliferation characteristics of one fuel cycle with an alternative fuel cycle, the analyst should develop high-level measures that are representative of the characteristics of the fuel cycle or part of a fuel cycle, rather than mixing characteristics of the fuel cycle and the proliferator. The analyst should also develop metrics for evaluation in a manner to minimize dependencies between the metrics as they affect the high level measures. A typical top-level measure is either proliferation resistance, which is a characteristic of a fuel cycle system, or proliferation risk, which also includes aspects of the proliferator. 
Table 2. Proliferation Barriers

\begin{tabular}{|c|c|c|}
\hline Barriertype & 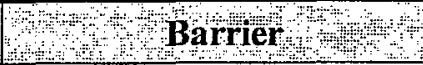 & 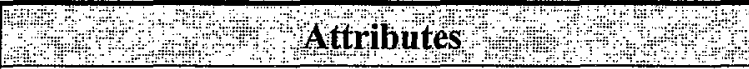 \\
\hline \multirow[t]{5}{*}{$\begin{array}{l}\text { Material } \\
\text { barriers }\end{array}$} & Isotopic & $\begin{array}{l}\text { Critical mass } \\
\text { Degree of isotopic enrichment } \\
\text { Spontaneous neutron generation } \\
\text { Heat generation rate } \\
\text { Difficulty presented by radiation to weapons } \\
\text { design }\end{array}$ \\
\hline & Chemical & Degree of difficulty in refining weapons material \\
\hline & $\begin{array}{l}\text { Radiological (dose to } \\
\text { humans) }\end{array}$ & Degree of remote handling normally required \\
\hline & Mass and bulk & Concentration of material, ease of concealment \\
\hline & Detectability & $\begin{array}{l}\text { Degree of passive detection capability } \\
\text { Active detection capability } \\
\text { Hardness of radiation signature } \\
\text { Uniqueness of material's signatures } \\
\text { Uncertainties in detection equipment }\end{array}$ \\
\hline \multirow[t]{6}{*}{$\begin{array}{l}\text { Technical } \\
\text { barriers }\end{array}$} & $\begin{array}{l}\text { Facility unattractiveness } \\
\text { (degree of difficulty of } \\
\text { production of weapons } \\
\text { material inherent in a } \\
\text { facility) }\end{array}$ & $\begin{array}{l}\text { Complexity of required modifications } \\
\text { Cost of modifications } \\
\text { Safety implications of modifications } \\
\text { Time required to modify } \\
\text { Facility throughput } \\
\text { Effectiveness of observable environmental } \\
\text { signatures }\end{array}$ \\
\hline & Facility accessibility & $\begin{array}{l}\text { Difficulty and time to perform operations } \\
\text { Need for specialized equipment } \\
\text { Manual versus automatic, remote operation } \\
\text { Frequency of operational opportunity to divert }\end{array}$ \\
\hline & Available mass & $\begin{array}{l}\text { Amount of potentially weapons useable material } \\
\text { at a given point in a fuel cycle }\end{array}$ \\
\hline & Diversion detectability & $\begin{array}{l}\text { Type of material and processes with respect to } \\
\text { accountability } \\
\text { Uncertainties in detection equipment } \\
\text { Form of material as amenable to counting }\end{array}$ \\
\hline & $\begin{array}{l}\text { Skills, expertise and } \\
\text { knowledge }\end{array}$ & $\begin{array}{l}\text { Dual-use skills and knowledge } \\
\text { Applicability of dual-use skills } \\
\text { Availability of dual-use information }\end{array}$ \\
\hline & Time & $\begin{array}{l}\text { Time materials in a facility or process are } \\
\text { available to proliferator access }\end{array}$ \\
\hline \multirow[t]{3}{*}{$\begin{array}{l}\text { Extrinsic } \\
\text { (Institutional) } \\
\text { barriers }\end{array}$} & Safeguards & $\begin{array}{l}\text { Availability and access to information } \\
\text { Minimum detectabilty limits for material } \\
\text { Ability to detect illicit activities } \\
\text { Response time of detectors and monitors } \\
\text { Precision and frequency of monitoring } \\
\text { Degree of incorporation into process design and } \\
\text { operation }\end{array}$ \\
\hline & Access control and security & $\begin{array}{l}\text { Administrative steps for access } \\
\text { Physical protection and security arrangements } \\
\text { Existence of effective back-up support } \\
\text { Effectiveness of access control and security }\end{array}$ \\
\hline & Location & Remoteness and/or co-location of facilities \\
\hline
\end{tabular}


Table 3. Threat Categories

\begin{tabular}{|c|c|c|c|c|c|c|}
\hline Threat & 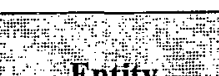 & my & Nom & Weapon As & rations & $\mathrm{Ptw}_{4}$ \\
\hline Categories & $t^{2}+4$ & Number & Yyeld & Réliability & Delivery & Stockpile \\
\hline 1 & C. & 1 or 2 & Any & Any & Truck/boat & No \\
\hline 2 & & 5 to 10. & Any & Any & Truck/boat & No \\
\hline 3 & & 1 or 2 & Any to $20 \mathrm{kt}$ & $50-95$ & Plane & Maybe \\
\hline 4 & Industrialized & 5 to 10 & Any to $20 \mathrm{kt}$ & $50-95$ & Plane & Maybe \\
\hline 5 & & 10 to 50 & Any to $20 \mathrm{kt}$ & $50-95$ & Plane & Maybe \\
\hline 6 & & 1 or 2 & Any to $20 \mathrm{kt}$ & $50-95$ & Plane & No \\
\hline 7 & $\begin{array}{l}\text { Developed } \\
\text { State }\end{array}$ & 5 to 10 & Any to $20 \mathrm{kt}$ & 95 & Plane & Yes \\
\hline 8 & & 10 to 50 & 20 to $200 \mathrm{kt}$ & 95 & Missile & Yes \\
\hline
\end{tabular}

\section{System Segmentation}

A nonproliferation issue relates to some type of system composed of facilities, processes, and controls. Frequently the system is an element or multiple elements of a fuel cycle system (for example, the element could be an enrichment facility). It is general practice to subdivide the system into discrete segments. The subdivision often occurs at the facility level, as illustrated in Figure 5. However, depending on the detail of the analysis approach, it may be necessary to further subdivide these facilities to the level of a distinct process line. For example, in the example in Figure 5, within the nuclear power plant, the accessibility and characteristics of fuel are different in the fresh fuel storage area, reactor core, and spent fuel storage pool. Thus, the nuclear power plant is subdivided into three elements. Similarly, at the ultimate storage facility, accessibility of material is different in the surface facilities than in the subsurface facilities. Once again, this facility is subdivided into two subunits for analysis. In contrast, the facilities at the front end of the fuel cycle involve only natural uranium, which is not a key target of proliferation. A number of facilities have been aggregated. Transportation between facilities can also be a point of diversion. Important transportation links can be identified as segments of the fuel cycle system in the same manner as facilities.

Typically, the analyst will compare the proliferation resistance of Fuel Cycle A for Threat 1 with the proliferation resistance of Fuel Cycle B for Threat 1 and similarly the resistance of the Fuel Cycle A for Threat 2 with the resistance of Fuel Cycle B for Threat 2, as illustrated in Figure 6. The analyst examines the proliferation resistance of each segment of the fuel cycle separately for each threat. 


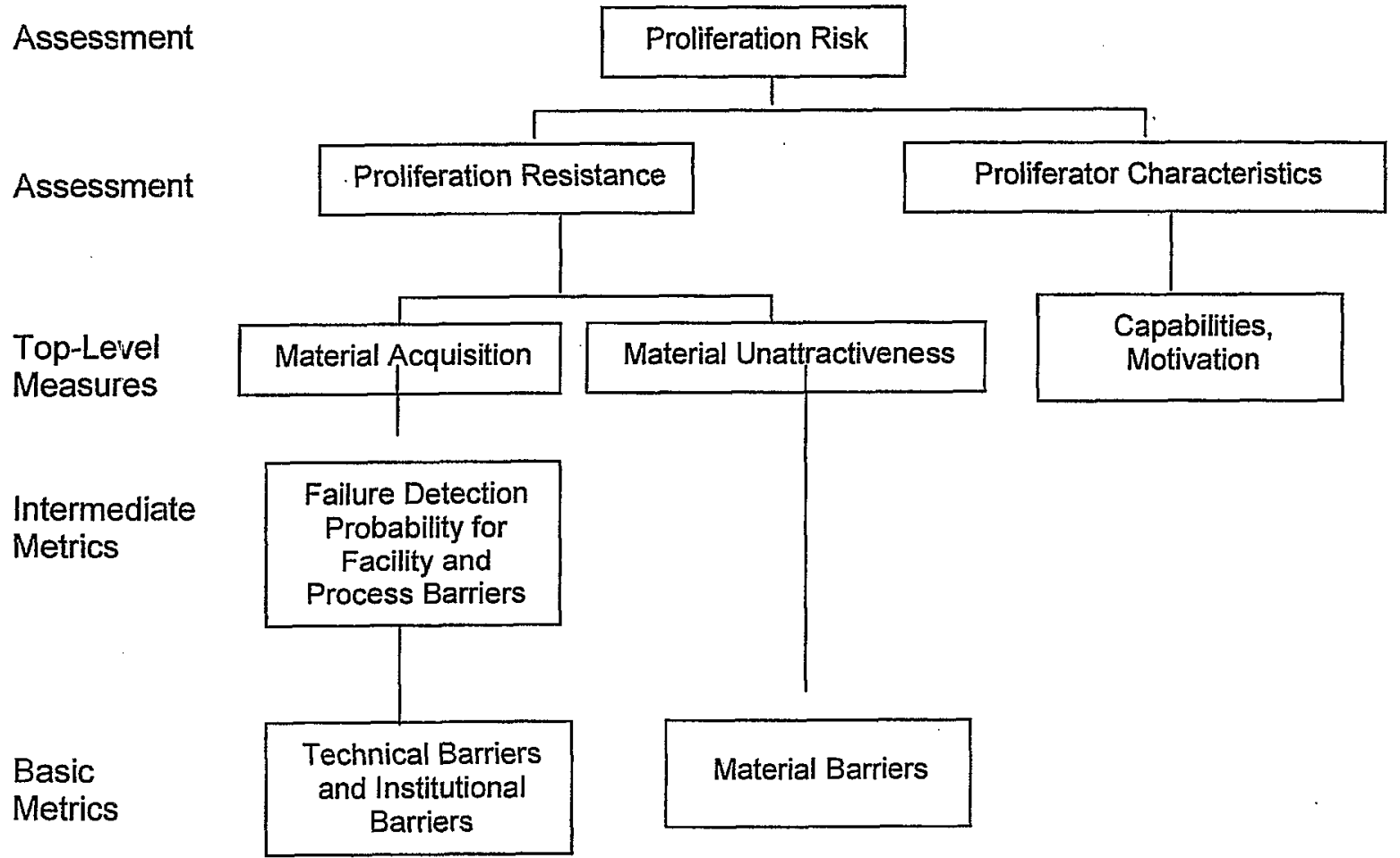

Figure 4. Hierarchy of Metrics 


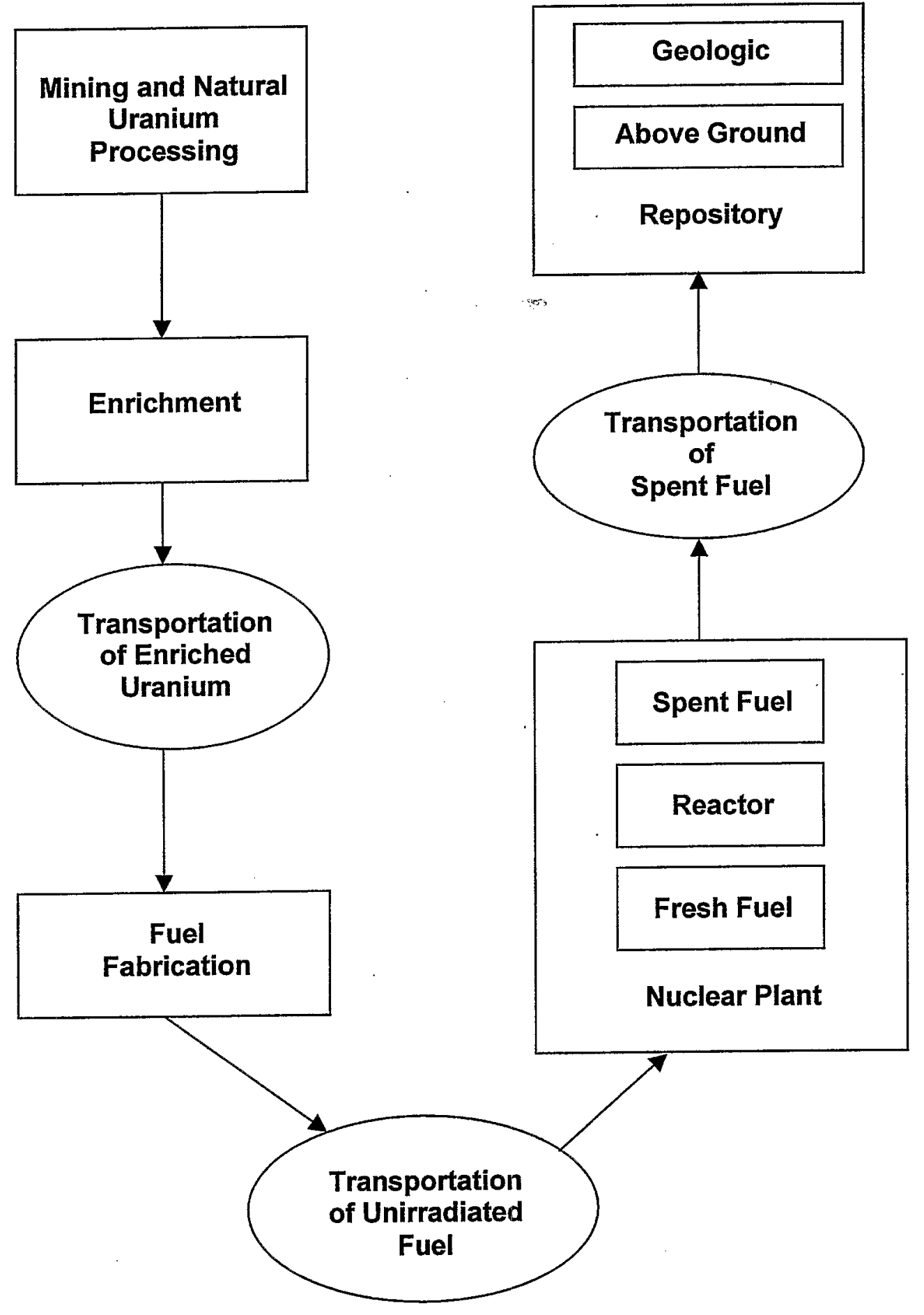

Figure 5. Segmentation of Fuel Cycle 

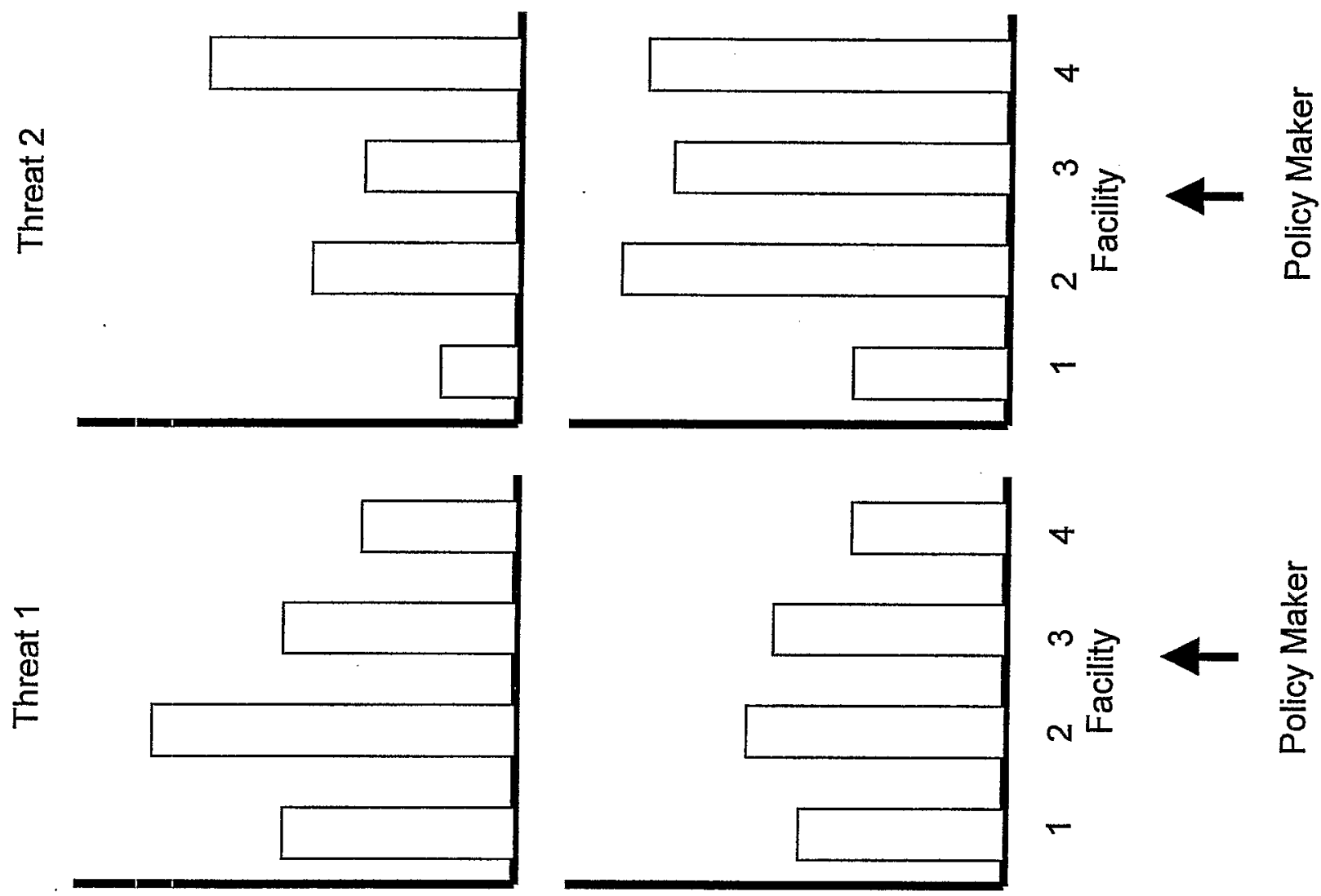

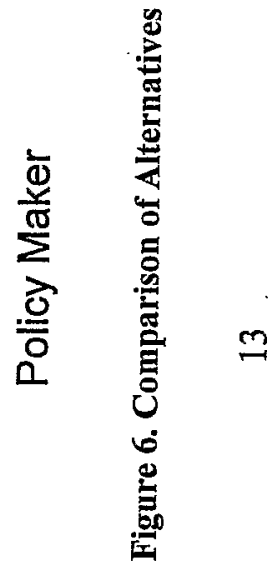

әouełs!̣səy uo!̣ejəy!|jodd

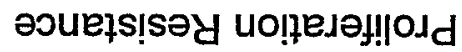
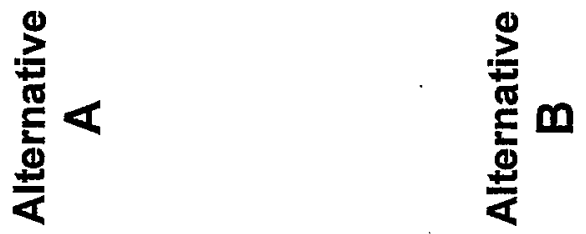


\section{Aggregation and Presentation of Results}

Figure 7 illustrates how the analysis is typically performed from the decomposed elements. The down and up arrows indicate an iteration over each of the elements in the top box. Thus, the complete analysis is performed for the first alternative and then for the second alternative. Within the analysis for each alternative, an assessment is made for each threat. Within each alternative and threat, an assessment is made for each segment of the fuel cycle (facility). The dashed box indicates the proliferation measurement algorithm, either a scenario analysis or an attribute analysis. For each alternative/threat/facility, the assessment measures the applicable barriers to proliferation. The weighting of metrics may occur within the measurement algorithm, or it may occur, as indicated in the figure, as a weighting of high-level metrics before the comparison of alternatives.

Two integrated methodologies are described in appendices to the guidelines document. The Risk-Informed Proliferation Analysis Methodology (RIPA) [4] is a scenario analysis approach that uses influence diagrams. The TOPS Barrier Analysis Method [5] is an attribute analysis approach. Both of these integrated methodologies are only in the development stage. Recommendations are made in this report for application studies in which these types of integrated methodologies would be further developed and evaluated. The aggregation of results and display of results are areas that are particularly in need of development.

\section{Conclusions}

The guidelines document has advanced the process of developing integrated methodologies to address nonproliferation issues. Building upon previous work, the document takes the next step towards achieving a hierarchy of methodologies that can be employed with confidence, and that will be credible to a wide range of nonproliferation analysts and policy makers. A peer review of this work has been conducted by a group of experts in the area of nonproliferation assessment methods. The overall impact of this peer review was to validate the approach taken in the study and to assure the completeness of the methods surveyed and recommended.

Nonproliferation problems tend to be complex, and have defied the development of a universally agreed upon assessment methodology. However, there have been a number of attempts to apply rigorous methodologies to proliferation assessment problems. A number of promising techniques were identified during this development project. These analytical tools, often developed for analysis of other problems, can potentially be applied to nonproliferation assessments. Many of these tools will also be helpful in the development of integrated methodologies.

The study identified three general categories of analytical approaches with excellent potential for use in nonproliferation studies: attribute analysis, scenario analysis, and two-sided methods. Attribute analyses evaluate the effectiveness of barriers to proliferation, scenario analyses assess the pathways through those barriers, and the twosided approaches explore the human interplay between adversaries. The three categories of approach are complementary in addressing the spectrum of nonproliferation issues that may be examined by NNSA and others. 


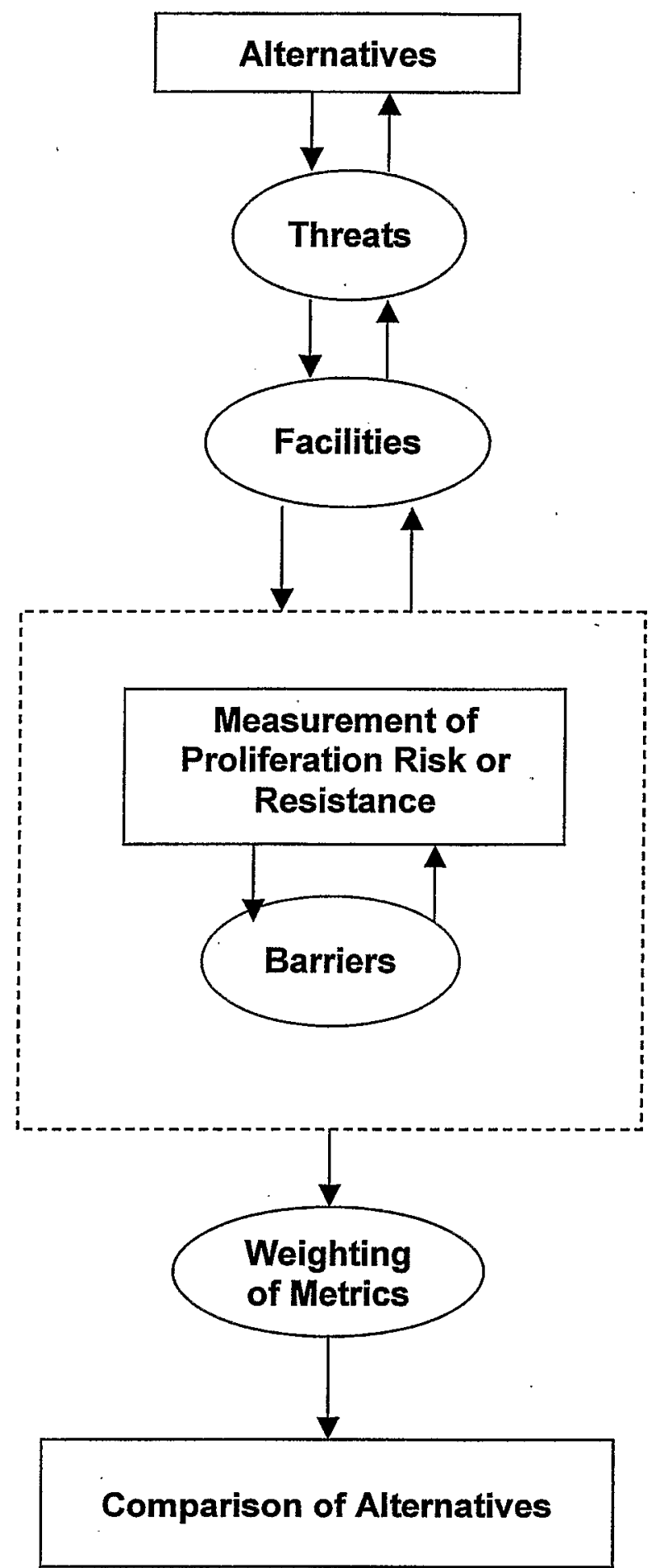

Figure 7. Typical Problem Decomposition and Analysis Flow 
Scenario analysis and attribute analysis methods can be used as the basis for integrated analysis approaches to the evaluation of the proliferation resistance or proliferation risk. of nuclear systems. Two-sided methods, in particular wargames, can be used to examine proliferation issues that involve the interplay of opponents with opposing objectives. Each of these general approaches can employ one or more of the analytical tools identified in the study. For example, the scenario analysis and attribute analysis methods could each employ an analytical hierarchy process to systematically incorporate expert opinion into the weighting of metrics.

No fully mature integrated methods are available to assess proliferation risk or proliferation resistance. Before any integrated method can be used routinely, it will have to be tested and further developed through the performance of application studies. Scenario analysis and attribute analysis approaches have different strengths and weaknesses, which make one or the other preferable for a given application. The two methods can also be used effectively together.

Two very promising integrated methods, an attribute-based approach and a scenariobased approach, are described in this report. The Multi-Attribute Utility Barrier Analysis method and the Risk-Informed Proliferation Analysis methods have been partially developed but would require additional development effort to be used in a study. Although wargames are widely used in other fields, there are only limited examples of their use in examining nonproliferation issues.

A significant challenge to the development and application of integrated assessment methodologies is the selection of appropriate metrics. This document presents a hierarchy of metrics that can be used to convey the results of the assessment. There is a great deal of information produced in a nonproliferation study that must be presented to the policy maker in a manner that can be properly interpreted. Some aggregation of results must be made in the analysis to make the results interpretable. This presents a challenge for any of the methods that have been surveyed. The aggregation of metrics must be done in a manner that avoids loss of information, minimizes interdependencies, is traceable and provides useable information to the policy-makers. Detailed results should be documented to enable the policy maker to be able to trace higher-level results back to their lower-level causes.

NNSA, in collaboration with the Office of Nuclear Energy, Science and Technology of the Department of Energy, is currently applying the guidelines developed in this study to the formulation of an evaluation methodology for proliferation resistance of Generation IV nuclear energy systems.

\section{Acknowledgements}

This work was performed for the NA-241 Division of the U. S. National Nuclear Security Administration under the guidance of Jon Phillips. We thank Suzanne McGuire, the NNSA project manager, for helpful support throughout the course of this work. We also acknowledge the contributions of our colleagues James Eagle, Chad Olinger, Gary Rochau, and Robert Schock to this project. 


\section{REFERENCES}

[1] NNSA, "Guidelines for the Performance of Nonproliferation Assessments," (draft) November 2002, (final) mid-2003.

[2] Perla, Peter, The Art of Wargaming, Naval Institute Press, 1990.

[3] Saaty, T.L., The Analytic Hierarchy Process, McGraw-Hill, ISBN 0-07-054371-2, 1980 .

[4] Rochau, G. E. et al, "Risk-Informed Proliferation Analysis," Sandia National Laboratories Report, SAND2001-2020, June, 2002.

[5] NERA.C, TOPS Task Force, "Annex: Attributes of Proliferation Resistance for Civilian Nuclear Power Systems," USDOE, October 2000. Available at: http://www.nuclear.gov/nerac/FinalTOPSRptAnnex.pdf 